\title{
PROGRAMAS NARRATIVOS DE LA NOVELA CHILENA EN EL SIGLO XX
}

\author{
POR \\ José Promis \\ University of Arizona, USA \\ Universidad de Playa Ancha, Chile
}

Al colocar el objeto cultural que identificamos con la designación de novela chilena del siglo $X X$ bajo la mirada retrospectiva que permite asumir el cercano desenlace de nuestro siglo, se descubre con facilidad la presencia de cinco programas narrativos que, cada uno a su turno, han marcado el desarrollo del género desde las proximidades de 1900 en adelante. Considerados en su totalidad, estos cinco programas constituyen el modelo que describe la dinámica del género a lo largo de casi cien años de su evolución. Hasta cierto punto, el esquema que se pretende delinear demuestra que las formas narrativas actualizadas por la novela chilena durante el presente siglo iluminan una estructura modélica que, conservando diferencias específicas con el desarrollo del género en otros países, constituye un paradigma aproximado del modo como ha evolucionado en general la novela hispanoamericana del siglo XX. ${ }^{1}$

En Chile, al igual que en el resto de Hispanoamérica, el siglo XX se inaugura con la hegemonía del programa de la novela de la descristalización impuesto por el naturalismo literario. Iniciado a fines del siglo XIX, este programa asigna a la novela una utilidad social específica: colaborar al conocimiento y a la corrección de los errores y desequilibrios humanos y sociales que el novelista descubre en la realidad de sus lectores. Por eso, una de las principales características que asume el discurso narrativo es el alto grado de transparencia con que pretende comunicar la imagen literaria de tal realidad. La novela de la descristalización se funda así sobre los criterios veristas característicos de la novela decimonónica y mantiene vigente su propósito de satisfacer las expectativas de lectores para quienes la novela es un texto cuya lectura debe remitir la atención del destinatario hacia sus propias circunstancias y experiencias inmediatas, hacia su mundo de lectores. La novela pretende convencer al lector de aquello que en su discurso se afirma como verdadero o como falso; de comprobar que las verdades comunicadas a través de los contenidos de la representación son o deben ser consideradas las "auténticas" verdades del mundo del lector así como las falsedades corresponden también a errores característicos del contexto extraliterario. El texto narrativo adquiere de esta manera el prestigio de ser una disección autorizada del comportamiento real, un texto que se ofrece al lector como

\footnotetext{
${ }^{1}$ José Promis. "En torno a la nueva novela hispanoamericana: reubicación de un concepto". Chasqui. Revista de literatura hispanoamericana 7.1 (1977).
} 
solución de los problemas y desequilibrios de su vida cotidiana. El valor de la literatura no radica primariamente en su estatuto artístico, sino en su carácter de documento, estudio o análisis sobre el momento social focalizado por el autor. El texto literario es entendido ante todo como investigación de la vida a distintos niveles socio-históricos o como estudio psicológico de un tipo humano característico. ${ }^{2}$

La sensibilidad naturalista vigente a comienzos de siglo asigna así a la novela una función inequívocamente descristalizadora, (a) la cual se entiende como denuncia y destrucción del carácter falso y engañoso de las interpretaciones de la realidad y de las consecuentes caracterizaciones de los motivos propuestas en el discurso narrativo de los novelistas románticos de la segunda mitad del siglo XIX. ${ }^{3}$ Por lo tanto, el término "romanticismo" y sus derivados se utilizan desde temprano en el lenguaje naturalista como sinónimos de falsedad, engaño de los sentidos e ignorancia de las verdaderas normas reguladoras del comportamiento. Consecuentemente, el discurso narrativo romántico se convierte en el genotexto donde los narradores naturalistas encuentran sus asuntos y repertorios de motivos. Así, por ejemplo, en el discurso de uno de los textos fundadores de este programa: Marianita (1885), de Vicente Grez, "lo romántico" aparece ya como equivalente a un concepto libresco, anticuado y falso de los comportamientos humanos. Laura, participante de la historia de amor funesto entre Marianita y Camilo, es descrita por el narrador como una mujer que "poseía un falso y romántico ideal de la vida, que a los ojos poco perspicaces de sus amigos pasaba por la más encantadora inocencia". El comportamiento de Camilo, el anti-héroe del relato que causará la muerte de Marianita, es interpretado por el narrador como manifestación de la ignorancia de la vida que se produce cuando la percepción de la realidad ha sido mediatizada por los falsos mitos románticos. Por eso sus amigos "exageraban sus actitudes románticas y sus paseos a la luz de la luna, y se burlaban de sus ternezas ya pasadas de moda y propias sólo de un idilio a lo Pablo y Virginia, pero de ninguna manera de un bachiller en humanidades, ya un poco crecido, de la Universidad de Santiago".

Si bien es cierto que en los comienzos de este programa narrativo la intención descristalizadora se orienta de preferencia a denunciar los mitos románticos del amor, muy pronto adquiere carácter de función dominante del relato. Los novelistas de comienzos de siglo inician así un proceso de descristalización que abarca todas las manifestaciones del comportamiento social "cristalizadas" por las erróneas percepciones de la realidad ofrecidas en el discurso literario del romanticismo decimonónico. Las "buenas costumbres" de la sociedad burguesa de comienzos de siglo son descristalizadas patéticamente por el narrador de Juana Lucero (1902), de Augusto D'Halmar. La función narrativa predominante de Casa Grande (1908), de Luis Orrego Luco, es destruir no sólo las cristalizadas

\footnotetext{
${ }^{2}$ El énfasis que coloca la novela modernista en el carácter artístico de su discurso parecería desmentir estas afirmaciones, pero la función que se asigna dominantemente al texto corresponde a la descristalización de una realidad mentida.

${ }^{3}$ En su significado más ceñido, el término "descristalización" se refiere específicamente al procedimiento utilizado por los escritores naturalistas para destruir el modo en que los escritores románticos habían interpretado el proceso amoroso, y sobre el cual Stendhal teorizó en su ensayo Del amor.
} 
preconcepciones de los jóvenes sobre el amor, sino también la falsa imagen de la perfectibilidad social con que la burguesía de la época percibía a la aristocracia, y su equivocada creencia en el poder del dinero para obtener la felicidad. En este aspecto, el discurso de Joaquín Edwards Bello se presenta como el gran descristalizador de los mitos románticos de fin de siglo. El texto de El roto (1920), por ejemplo, destruye la figura del "roto" como símbolo nacionalista de los valores de la chilenidad y el de La chica del Crillón (1935) desempeña una función similar a la que exhibía Casa Grande, pero focalizándose de preferencia en el mundo de los arribistas burgueses de Santiago. Por su parte, Un perdido (1918), de Eduardo Barrios, constituye la descristalización del mito romántico de la energía individual y Zurzulita (1920), de Mariano Latorre, descristaliza la imagen idílica de la naturaleza como espacio de bondad e ingenuidad moral.

A partir del momento en que la función descristalizadora impuesta a la novela chilena por el positivismo literario entra a su etapa de agotamiento histórico - aproximadamente a partir de la década de las vanguardias- el género se ha desarrollado a través de cuatro programas narrativos cuyas primeras manifestaciones han surgido entramadas con las preferencias impuestas por el programa anterior, pero cuyos momentos de madurez exhiben notas características de indudable identidad histórica. ${ }^{4}$ El primer programa corresponde a la novela del fundamento, programa que se genera como alternativa a los agotados sistemas de interpretación y a las formas narrativas que había impuesto el pensamiento positivista. En oposición al concepto documental y a la función descristalizadora asumidas por la narración de base naturalista, la novela del fundamento responde a un concepto del género entendido como un "saber de salvación". El proceso narrativo adquiere la forma de una indagación lingüística que se orienta hacia el descubrimiento y la revelación de profundos, secretos y desconocidos conflictos individuales. Los narradores chilenos que inauguran este programa se muestran unánimes para descalificar a los grandes novelistas telúricos como escritores incapaces de ver más allá de los fenómenos que caían bajo su percepción inmediata, bajo el escrutinio de su mirada. Según Manuel Rojas, por ejemplo, cuyas novelas constituyen sobresalientes modalidades de este programa, que un escritor se declarase narrador costumbrista era una forma de autorreconocer sus menguadas capacidades artísticas. Por esta razón, durante la década de los años treinta Manuel Rojas criticó con acritud la obra de Mariano Latorre - la figura más prominente del llamado "criollismo" chileno- porque descubría en su producción narrativa el arquetipo literario que rechazaba de manera inapelable. ${ }^{5}$

En el programa impuesto por la novela del fundamento, los asuntos telúricos de la novela naturalista son ignorados o convertidos en motivos decoradores del espacio narrativo. El medio deja de ser interpretado como el factor fundamental que determina el comportamiento humano y a lo sumo se lo conserva como ambientación del conflicto. Por esta razón, la lectura de tales relatos dejó insatisfechas las expectativas de muchos críticos

${ }^{4}$ El desarrollo de estos programas narrativos se corresponde, aunque no absolutamente, con la actividad de las sucesivas generaciones de escritores chilenos establecidas en La novela chilena. Los mitos degradados, de Cedomil Goic, 1968 ( $5^{\mathrm{a}}$ edición) (Santiago: Editorial Universitaria, 1991). ${ }^{5}$ Manuel Rojas. De la poesía a la revolución (Santiago: Editorial Ercilla, 1938); El árbol siempre verde (Santiago: Editorial Zig-Zag, 1960). 
positivistas y la percepción que tuvieron de estas novelas fue, en consecuencia, más bien confusa. Acostumbrados a la representación naturalista de los conflictos telúricos, se desorientaron al enfrentarse a textos que alteraban considerablemente la jerarquía que hasta entonces habían exhibido los elementos de la estructura narrativa. Se acuñó entonces la expresión neo-criollismo para referirse al conjunto de estas novelas, designación cuyo prefijo "neo" no hacía otra cosa que ocultar la incapacidad del discurso crítico de la época para responder adecuadamente a las nuevas expectativas de lectura que inauguraban tales relatos.

La novela del fundamento rechaza las explicaciones positivistas sobre el sentido y el destino del comportamiento humano, pero no propone ninguna alternativa. Su programa se desarrolla en torno al motivo de la "búsqueda", continuando, en este aspecto, una preferencia narrativa característica de la novela modernista durante el período finisecular. Los personajes y narradores de este programa actúan al servicio de una función indagatoria; son elementos que el autor utiliza para rastrear los orígenes, las causas, las ocultas razones que permitan explicar los desequilibrios que los narradores descubren en la realidad inmediata. En muchos casos son personajes tránsfugas, tal como ocurre, por ejemplo, en relatos de Marta Brunet, donde los individuos abandonan determinados espacios creyendo que en otro medio encontrarán las respuestas o los equilibrios que el espacio desechado no les otorga. Su experiencia demuestra la inutilidad del desplazamiento espacial porque las respuestas anheladas debieran buscarlas en el interior de la propia conciencia. En otros casos, se trata de personajes marginales o vagabundos cuya precariedad individual no alcanza a proyectarse hacia una situación social totalizadora. En este sentido, la novela del fundamento propone con frecuencia que la reconciliación consigo mismo es el principal requisito que el ser humano debe satisfacer como condición previa para descubrir su lugar en el mundo, descubrimiento que no necesariamente significa escapar de la indefensión o la precariedad que marca a la existencia humana, sino compartirla a través del encuentro con el otro y de la solidaridad nacida del auténtico vínculo humano.

Como su nombre lo indica, el programa narrativo de la novela del fundamento se orienta hacia la revelación de los verdaderos y profundos factores que determinan y prestan sentido a la existencia humana, pero al proyectar preferentemente su foco narrativo sobre situaciones individuales específicas no llega a establecer un sistema general de interpretación como el que había propuesto la novela de la descristalización. Debido a ello es que las expectativas ofrecidas en muchas de sus historias quedan sin respuesta, situación que determina los desenlaces abiertos de sus relatos, o sus soluciones elaboradas de acuerdo a explicaciones metafísicas sobre el sentido del comportamiento humano. ${ }^{6}$

El segundo programa narrativo que marca el desarrollo de la novela chilena del siglo $\mathrm{XX}$ corresponde a la novela del acoso, que se generó como alternativa de las interpretaciones ofrecidas por la novela del fundamento. Este programa concibe la existencia humana como una situación de asedio permanente y proyecta su foco narrativo sobre dos conflictos histórico-sociales característicos: el de la opresión del proletariado en la sociedad capitalista

\footnotetext{
${ }^{6}$ Entre los novelistas más conocidos de este programa se pueden recordar los nombres de Marta Brunet, Juan Emar, Vicente Huidobro, Diego Muñoz, Manuel Rojas, Carlos Sepúlveda Leyton y María Flora Yánez.
} 
y el de la opresión de la mujer en la sociedad masculina. Ambos conflictos son interpretados como manifestaciones homólogas de una estructura histórica común que la novela del acoso representa a nivel artístico mediante una imagen circular de la existencia humana. El centro de este círculo es identificado con la imagen de la familia proletaria o con la imagen de la mujer, y encierra los valores que la perspectiva ética del narrador percibe como auténticos. El entorno, por su parte, es el espacio donde radican los valores que esa misma perspectiva define como falsos o degradados - es decir, inauténticos- y a los cuales el narrador identifica con los comportamientos deshumanizados de la sociedad capitalista o con las normas impuestas por el hombre para subyugar e incluso destruir la expresión de la naturaleza femenina esencial.

En el programa de la novela del acoso el sentido del comportamiento humano se manifiesta en el esfuerzo con que el centro defiende la conservación de sus valores contra los ataques violentos e inclementes con que el entorno pretende destruirlos. Ya sea que se trate de los esfuerzos de los intereses capitalistas para quebrar la solidaridad del proletariado, o de los esfuerzos de las normas sociales impuestas por los hombres para subyugar a la mujer, el contacto entre ambos espacios es siempre representado como una situación de acoso permanente, de esfuerzo de dominio de una clase social sobre otra clase social o de un sexo sobre el otro. Estos relatos proponen, sin embargo, que si bien el centro vive agobiado por el poder superior del entorno, su sobrevivencia, aunque dolorosa, es posible en la medida en que el centro es capaz de mantener incólumes los valores auténticos que conserva en su interior. El "acoso" es, pues, el motivo dominante de su programa narrativo.

La novela del acoso origina dos variantes narrativas características de acuerdo a la manera como es representado el centro de la realidad histórica: la novela de tendencia social y la novela femenina. Si bien es cierto que en ambas tendencias se percibe la manifestación de una perspectiva de tonos sombríos y de un temple de ánimo marcado por un doloroso pesimismo, es en el discurso de la novela femenina de la época donde se enfatiza con frecuencia la desesperación de la voz narrativa al contemplar cercenada cualquier posibilidad de evasión o de triunfo para sus protagonistas. Por lo mismo, la única puerta de escape que muchas de estas novelas descubren para la mujer que se asfixia dentro del sistema de normas de comportamiento impuesto por el otro sexo, es el ensimismamiento, la ensoñación o, incluso, la muerte. ${ }^{?}$

El tercer programa narrativo que ha dominado el espacio de la novela chilena durante el siglo XX comienza a gestarse al promediar la mitad del siglo y toma cuerpo durante los años que la crítica literaria ha caracterizado - para bien o para mal-como el período del "boom" de la novela hispanoamericana. Es un programa que manifiesta desde sus comienzos una actitud de radical antagonismo tanto hacia las ofertas narrativas de la novela del fundamento como hacia las de la novela del acoso. Varios destacados narradores chilenos cuyos relatos contribuyeron a configurar este nuevo programa lo justificaron en la década de los años cincuenta como un sistema de preferencias que se originaba en el desencanto, el escepticismo y la angustia con que los jóvenes escritores de esos años percibían el

\footnotetext{
${ }^{7}$ Los representantes más conocidos de la novela del acoso han sido Fernando Alegría, Daniel Belmar, María Luisa Bombal, Óscar Castro, Francisco Coloane, Carlos Droguett, Juan Godoy, Nicomedes Guzmán, Reinaldo Lomboy, Chela Reyes, Volodia Teitemboim y María Flora Yánez.
} 
desarrollo histórico de su realidad político-social inmediata, de la realidad continental y de la realidad de Occidente. Debido a ello es que en el mundo imaginario de esta novela, la realidad vive un proceso de descalabro y desmoronamiento irreversibles. Pero a la vez, también este programa narrativo surge como consecuencia de la desconfianza y descrédito hacia las formas narrativas que de dicha situación histórica se habían generado. ${ }^{8}$

Así, el programa de la novela del escepticismo surge como consecuencia de un nuevo sistema de intereses narrativos que focaliza la representación literaria en imágenes agónicas de la existencia humana - individual y socialmente considerada — pero además es también el resultado de un concepto del relato que enfatiza su condición de estructura artística del lenguaje. Enrique Lafourcade ha dicho en más de una oportunidad que para los nuevos novelistas chilenos de los años cincuenta la obra literaria era, ante todo, un objeto estético cuyo valor representacional y artístico depende dominantemente de su propia construcción; es una novela del lenguaje puesta al servicio de representar la agonía existencial del ser humano contemporáneo.'

La lectura de los primeros relatos producidos por la novela del escepticismo condujo al discurso crítico de la época a definir este programa como una manifestación de novela "urbana" o "citadina", debido principalmente a que la representación tradicional de los ambientes rurales y de los conflictos campesinos había dejado paso al interés por representar de preferencia los problemas existenciales de la alta burguesía santiaguina. A la luz con que los ilumina la perspectiva escéptica de la mayoría de sus narradores, tales conflictos asumen por lo general la forma de procesos de agonía irrecuperables. La mayor parte de los personajes presentados en esta novela constituyen una galería de seres exhaustos, débiles, o desquiciados, quienes tratan infructuosamente de obtener una última posibilidad de recuperación vital después de haber malgastado todas sus oportunidades anteriores. El estancamiento existencial es una de las notas más acentuadas de su conciencia, característica que puede llegar a manifestarse en inmovilidad física o en tortuosidades mentales que crean imágenes análogas y reversibles, pero siempre anémicas, decadentes e, incluso, pesadillescas, del espacio en que se desenvuelven.

Consecuentemente, la "caída" y la "nostalgia del paraíso perdido" son dos de los motivos narrativos más característicos de esta novela. Narradores y personajes viven tratando de recuperar determinados espacios a los que su conciencia decrépita les confiere el prestigio de desaparecidos mundos de felicidad. La infructuosidad de sus esfuerzos determina que los relatos se cierren por lo general con secuencias narrativas que aluden al fracaso, la derrota y el definitivo desaparecimiento de toda esperanza. La posibilidad de cambio o de transformación está ausente de este sistema de preferencias; salvo en ciertas

\footnotetext{
${ }^{8}$ Giaconi, Claudio. "Una experiencia literaria", Atenea 380-381 (1958); Poblete Varas, Hernán, "Novelistas de hoy", Atenea 389 (1960). La más completa información sobre el polémico surgimiento de este programa narrativo se encuentra en el texto del profesor Eduardo Godoy Gallardo: La generación del 50 en Chile. Historia de un movimiento literario (Narrativa) (Santiago de Chile: Editorial La Noria, 1991).

${ }^{9}$ Lafourcade, Enrique. Antología del nuevo cuento en Chile (Santiago, 1954); "La generación del 50. Apuntes para una mitología", Cuadernos Americanos XXI, cxciii, 4 (1962).
} 
excepciones, ni siquiera la redención constituye una alternativa dentro de las opciones ofrecidas por el discurso narrativo. ${ }^{10}$

A fines de la década de los años sesenta, un nuevo proyecto narrativo en abierto y declarado antagonismo con el sistema de preferencias de la novela entonces dominante, es decir, de la novela del escepticismo, comienza a desarrollarse en Chile. Este proyecto nace de un esfuerzo consciente para superar las actitudes y los motivos literarios impuestos por el agonismo existencial de aquélla. El escepticismo, la desorientación vital, el desesperado anhelo de reencontrar inexistentes paraísos perdidos, la pérdida de la voluntad o el sentimiento de caída irrecuperable frente a un mundo del cual han desaparecido los órdenes protectores, formaban un código de preferencias narrativas que los nuevos relatos rechazan de plano. En su lugar, se pretende fundar un discurso narrativo originado en la voluntad para colocar la literatura al servicio de la representación de una épica cotidiana donde reaparece la confianza en las capacidades individuales y colectivas para instalarse triunfalmente en el mundo y construir una sociedad mejor. El nuevo programa narrativo se autodefine por lo tanto como un esfuerzo desacralizador de los esquemas impuestos por la novela del escepticismo. A diferencia de ésta, ofrece una confiada actitud de optimismo para superar los obstáculos inmediatos, impulsa una nueva ética a través de la recuperación de los placeres sensoriales, descubre en los modos cotidianos de comportamiento un repertorio favorito de asuntos literarios, recupera para el discurso una funcionalidad dominantemente narrativa al despojarlo de sus connotaciones de pesimismo existencial, e introduce en el lenguaje un vocabulario coloquial cargado de expresiones de intensa vitalidad cotidiana. Sus proposiciones manifiestan, sin duda alguna, el optimismo con que muchos chilenos vivían el momento histórico de renovación social y política que se comenzaba a experimentar en Chile a fines de esa década. ${ }^{11}$

El programa de la novela de la desacralización se vio dolorosamente interrumpido en el interior del país por el golpe de Estado de 1973. Mientras que numerosos escritores que lo representaban debieron salir al exilio, la producción narrativa de los demás fue silenciada o cercenada por la suspensión de la libertad de expresión y por la vigilancia de la censura de libros impuesta por la dictadura chilena. Sin embargo, el programa pronto se reanudó con la publicación de novelas chilenas en el extranjero y su desarrollo se vio también favorecido en el interior del país durante la década de los años ochenta gracias al progresivo agotamiento político de la dictadura, que entre otras cosas produjo la debilitación y final derogación de la censura editorial. Se puede afirmar, por lo tanto, que el proceso desacralizador llevado a cabo por este programa exhibe dos momentos claramente definidos: antes de 1973 se dirige principalmente a la desacralización de la imagen de la realidad y de

${ }^{10}$ Entre los novelistas más conocidos de este programa figuran, por ejemplo, Margarita Aguirre, Guillermo Blanco, Hugo Correa, Armando Cassígoli, Luis Domínguez, José Donoso, Jorge Edwards, Leonardo Espinoza, Pablo García, Walter Garib, María Elena Gertner, Jorge Guzmán, Enrique Lafourcade, Jaime Lazo, Hernán Poblete Varas, José Luis Rosasco, Elisa Serrana, Hernán Valdés, Mercedes Valdivieso y Luis Vulliamy.

${ }^{11}$ Poli Délano. "Apuntes sobre lo que se va dejando de llamar 'Las nuevas hornadas' de la narrativa chilena" Casa de las Américas 75 (1972); Antonio Skármeta. "La novísima generación: varias características y un límite", The American Hispanist 1,3 (1975). 
los modos narrativos impuestos por el programa de la novela del escepticismo; después de esa fecha su discurso asume una forma "contestataria" y su función narrativa se orienta al servicio de desacralizar las imágenes de prosperidad, felicidad y orden comunicadas por el discurso oficial de la dictadura. ${ }^{12}$

La novela chilena hoy en vigencia responde al sistema de opciones narrativas característico de la novela de la desacralización. A diferencia de los programas anteriores que, exceptuando la tendencia social impuesta por la novela del acoso, habían evitado generalmente el compromiso con las situaciones políticas inmediatas, la mayor parte de la novela actual se produce al servicio del testimonio y de la denuncia de los sufrimientos vividos dentro y fuera del país durante los años de la dictadura militar. El acto de narrar es percibido actualmente por el novelista chileno como un proceso de "escribir para que los hechos no se esfumen, para que la memoria no sea barrida por el viento. Escribir para registrar las cosas y nombrar las cosas. Escribir lo que no se debe olvidar". ${ }^{13}$ Consecuentemente, los narradores de la mayoría de los relatos de la novela de la desacralización asumen puntos de vista inquisitivos que les permiten denunciar, parodiar o satirizar situaciones y actitudes canonizadas, o se representan a sí mismos como cronistas del dolor, como testigos de una experiencia pesadillesca que han asumido la responsabilidad de dejar testimonio de la destrucción de un sistema social establecido, y de impedir que se olviden o se esfumen las imágenes del horror y de la tortura que dicha destrucción trajo como sus más funestas consecuencias.

Asumir tal responsabilidad narrativa significó al comienzo un verdadero desafío para los novelistas chilenos. Representar el referente histórico - la dictadura y sus violentos métodos de dominio y humillación humana - ofrecía obviamente riesgos considerables, sobre todo para los narradores que permanecían en el interior del país. Mientras que los narradores exiliados podían representar en sus discursos al referente de manera más directa, los relatos de la novela de la desacralización escritos en el interior del país durante la época de la dictadura desarrollan cuatro modos narrativos de representación indirecta que someramente enumerados pueden definirse así: la inversión del referente histórico, que consiste en construir un discurso narrativo de sintaxis y tono opuestos a la modalidades que exhibía el discurso oficial de la dictadura; la anulación explícita del referente, el cual, por lo tanto, se hace presente a través de insinuaciones y alusiones disfrazadas; la interiorización del referente, que consiste en reducir sus dimensiones al conflicto de una personalidad privada; $y$, finalmente, el deslizamiento del referente hacia el nivel del mito, convirtiéndolo así en un sistema de normas de dominación y oprobio universales que puede materializarse en cualquier espacio y tiempo particulares. ${ }^{14}$

\footnotetext{
${ }^{12}$ Después de 1973, numerosos representantes de los programas narrativos anteriores han orientado también su producción textual dentro de la segunda tendencia asumida por esta función desacralizadora. La forma "contestataria" de la novela chilena actual se ha convertido así en una estructura supra-programática que se manifiesta en la producción de novelistas pertenecientes a sucesivas generaciones históricas.

${ }^{13}$ Allende, Isabel. "Vamos a nombrar las cosas: una conferencia en Puerto Rico" La Época (Santiago de Chile, 6 y 7 de octubre de 1987).

14 José Promis. "Balance de la novela en Chile: 1973-1990", Hispamérica 19,55 (1990).
} 
El asunto de las dictaduras y los motivos de tortura y vejación humanas nunca habían pertenecido al repertorio argumental de la novela chilena. Su apropiación estética ha constituído, pues, el desafio al cual se han enfrentado la mayoría de los narradores de la novela de la desacralización casi desde los momentos iniciales de su programa narrativo. Naturalmente que hay textos que tratan de ignorarlo, pero incluso tales esfuerzos demuestran su hegemónica y atemorizante presencia, el perfil de la dictadura que sombrea y que continuará dominando la producción narrativa chilena todavía más allá del desenlace del presente siglo. ${ }^{15}$

\footnotetext{
${ }^{15}$ Entre los más conocidos representantes de la novela de la desacralización se puede recordar a Isabel Allende, Poli Délano, Luis Domínguez, Ariel Dorfman, Andrés Gallardo, Cristián Huneeus, Fernando Jerez, Patricio Manns, Carlos Morand, Francisco Simón Rivas, Antonio Skármeta y Mauricio Wacquez. Como tendencia dominante en la novela chilena, la desacralización no ha desaparecido de los relatos escritos por promociones de narradores más jóvenes: Marco Antonio de la Parra, Ana María del Río, Diamela Eltit, Reinaldo Edmundo Marchant, Antonio Ostornol, etc.
} 
